DOI: $\underline{\text { http://dx.doi.org/10.5007/1980-3532.2015n14p82 }}$

\title{
Práticas de escrita nas aulas de Sociologia: implicações para o processo de apropriação da linguagem sociológica
}

\author{
Writing practices in Sociology classes: implications for the \\ process of sociological language appropriation
}

Erika Kulessa

Mestranda em Educação (Universidade de São Paulo)

erikaksouza@gmail.com

\begin{abstract}
Resumo: Este artigo apresenta a problemática e alguns desdobramentos de uma pesquisa em curso sobre as questões de leitura e escrita envolvidas no ensino de Sociologia no Ensino Médio, em escolas públicas da região metropolitana de São Paulo. Considerando o cenário de grandes dificuldades que marcam tais praticas entre os brasileiros, inclusive enquanto frequentam a escola, discute-se suas implicações para o ensino e aprendizagem da disciplina. Apresenta-se uma metodologia e análise preliminar de produções escritas de estudantes em aulas de Sociologia, ponderando sobre as formas de mobilização do conhecimento, as características do discurso adotado e a relação entre os enunciados produzidos pelos estudantes e o trabalho pedagógico realizado durante o curso.
\end{abstract}

Palavras-chave: Ensino de sociologia; leitura e escrita. linguagem sociológica; Ensino Médio; usos da linguagem.

Abstract: This article presents the problems and some developments of an ongoing research on reading and writing issues involved in teaching Sociology in secondary schools, specially at public ones in the metropolitan area of São Paulo. The implications of the difficulties that characterizes such practices among Brazilians, even while attending school, for teaching and learning the discipline are discussed. The methodology and preliminary analysis of written productions of students in Sociology classes are presented, pondering on the ways students mobilize the knowledge, the characteristics of the speech they adopt and the relationship between the students texts and the pedagogical work carried out during the course.

Keywords: Teaching Sociology; reading and writing; sociological language; secondary school; uses of language.

Originais recebidos em: 29/02/2016

Aceito para publicação em: 13/05/2016

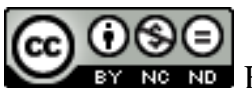
Comercial-Vedada a criação de obras derivadas 3.0 Unported License. 


\section{Apresentação}

O cenário da leitura e escrita no Brasil é desalentador, não obstante a expansão do acesso à educação básica nas últimas décadas. Em 2001, a primeira pesquisa do INAF (Indicador de Alfabetismo Funcional) apontava que apesar da redução das taxas de analfabetismo a $12 \%$, apenas $26 \%$ da população tomava parte em práticas letradas de forma plena ${ }^{1}$. Dez anos depois, o mesmo indicador apontava uma redução do índice de analfabetismo pela metade e um aumento considerável naquele que é classificado como nível básico (de 34 para 47\%). No entanto, a taxa daqueles que se considera plenamente alfabetizados permaneceu praticamente inalterada ao longo dos 10 anos em que se realizou a pesquisa (INAF, 2011).

O INAF não avalia conteúdos escolares e sim o uso que se faz da leitura e escrita em diversos contextos da vida social, fora da escola. Mas também no tocante ao que é esperado pela própria escola, os resultados não são mais razoáveis. No estado de São Paulo especificamente, a avaliação empreendida pela secretaria de educação, o SARESP (Sistema de Avaliação de Rendimento Escolar do Estado de São Paulo) apontou, em 2014, que ao final do Ensino Fundamental 26\% dos estudantes da rede estadual tem nível proficiência em leitura e redação considerado "abaixo do básico" e apenas 18\% alcança os níveis considerados "adequado" ou "avançado". Ao final do Ensino Médio, o índice de desempenho considerado "abaixo do básico" sobre para 37,4\% e os considerados "adequado" ou "avançado" aumentam modestamente para 25\% (RIBEIRO, 2003; SAO PAULO, 2015). ${ }^{2}$

Qual é o impacto dessa situação para o ensino das diversas disciplinas, para além de Língua Portuguesa, e o que é possível fazer diante dessa realidade? Quais estratégias adotar para que as dificuldades dos estudantes com a língua escrita não sejam o "pontapé em uma bola de neve", em que por estarem privados de um conhecimento, se lhes tira o direito a outros? De que forma os diferentes professores

1 O INAF considera quatro níveis de habilidades de leitura, escrita e cálculo matemático: analfabetismo, nível rudimentar, básico e pleno. Este último, considerado como aquele que deveria ser alcançado ao fim do ensino fundamental, é definido como "pessoas cujas habilidades não mais impõem restrições para compreender e interpretar textos em situações usuais: leem textos mais longos, analisando e relacionando suas partes, comparam e avaliam informações, distinguem fato de opinião, realizam inferências e sínteses. Quanto à matemática, resolvem problemas que exigem maior planejamento e controle, envolvendo percentuais, proporções e cálculo de área, além de interpretar tabelas de dupla entrada, mapas e gráficos" (INAF, 2012, p. 5).

2 O SARESP considera também quatro níveis de proficiência, sendo eles: "abaixo do básico", "básico", "adequado" e "avançado". No $9^{\circ}$ ano do Ensino Fundamental 16,1\% estariam no nível "adequado" e 1,9\% no "avançado" e no $3^{\circ}$ ano do Ensino Médio 24,4\% estariam no nível "adequado" e 0,6\% no "avançado" (SÃO PAULO, 2015). 
podem contribuir para mudar esse quadro, sem abandonar a tarefa de ensinar suas respectivas disciplinas? Pensando nessas questões, a pesquisa tem se debruçado, antes de mais nada, sobre o tipo de conhecimento que queremos promover com o ensino de Sociologia no nível médio e sobre o papel da leitura e da escrita nesse processo.

Não é demais ressaltar que aqui rejeita-se o pressuposto segundo o qual aprender a ler e escrever restrinja-se ao domínio de um código que pode ser acionado nas mais variadas situações em que estão envolvidas práticas letradas. Os usos da linguagem escrita são muito diversos e é somente em contato com as diferentes práticas que se aprende a lidar com cada uma delas. Ao ingressar no Ensino Médio os estudantes conhecem novas disciplinas, que lhes apresentam conhecimentos, textos e discursos com os quais é necessário familiarizar-se. Sendo assim, a pesquisa buscou identificar as especificidades trazidas pela disciplina Sociologia e voltou o olhar para o processo de apropriação da linguagem sociológica por parte dos estudantes, ou seja, a possibilidade de que os estudantes façam uso autônomo dos conhecimentos trabalhados na disciplina na sua interpretação da realidade.

Assim como o conhecimento da vida social que se busca promover e socializar nas aulas de Sociologia difere do conhecimento cotidiano, popular, também a linguagem em torno do qual está organizado difere da linguagem corrente (BOURDIEU, CHAMBOREDON e PASSERON, 2000). Compreender a especificidade da linguagem sociológica é um primeiro aspecto da dimensão linguística do ensino de Sociologia que parece fundamental considerar para responder às questões que norteiam essa pesquisa.

Recorrendo a Bakhtin (2003), pode-se delinear uma definição da linguagem sociológica a partir da distinção dos gêneros do discurso entre primários e secundários.

Aqui é de especial importância atentar para a diferença essencial entre os gêneros discursivos primários (simples) e secundários (complexos) - não se trata de uma diferença funcional. Os gêneros discursivos secundários (complexos - romances, dramas, pesquisas científicas de toda a espécie, os grandes gêneros publicísticos, etc.) surgem nas condições de um convívio cultural mais complexo e relativamente muito desenvolvido e organizado (predominantemente escrito) - artístico, científico, sociopolítico, etc. No processo de sua formação eles incorporam e reelaboram diversos gêneros primários (simples), que se formaram nas condições de comunicação discursiva imediata (p. 263).

Dessa forma, os discursos primários são aqueles que surgem de forma espontânea na interação verbal, fazendo referência apenas ao contexto imediato que os suscita. Já os discursos secundários, são mais complexos e constituem uma reinterpretação da experiência imediata. Com relação especificamente à linguagem das 
Ciências Humanas, estamos ainda diante de "pensamentos sobre pensamentos, vivências sobre vivências, palavras sobre palavras, textos sobre textos" (ibidem, p. 307). Assim, a linguagem reflexiva, conceitual e abstrata da Sociologia constitui um discurso de tipo secundário, que toma a vida social enquanto objeto de conhecimento e, além disso, que se dedica a refletir sobre pensamentos e discursos alheios.

Aprofundando tal definição a partir das reflexões no campo da epistemologia das Ciências Sociais, vemos que a linguagem sociológica em si também pode ser entendida como um tipo particular de discurso, que tem sua unidade gerada pela conformidade com certas "regras" de produção do conhecimento sociológico.

A teoria do conhecimento sociológico, como sistema de regras que regem a
produção de todos os atos e discursos sociológicos possíveis, e somente
destes, é o princípio gerador das diferentes teorias parciais do social (quer se
trate, por exemplo, da teoria das trocas matrimoniais ou da teoria da difusão
cultural) e, por consequência, o princípio unificador do discurso
propriamente sociológico, que não deve ser confundido com uma teoria
unitária do social (BOURDIEU, CHAMBOREDON, PASSERON, 2000, p.
43, grifo meu).

Não se trata aqui de métodos ou técnicas de pesquisa, mas de um modus operandi, que passa pela busca de explicações sociais para o social, pelo esforço de reconstruir os fenômenos e fatos sociais como objetos científicos e pelo exercício de uma “dúvida radical”, nos termos de Bourdieu (2011), em relação às pré-construções do senso comum. Essa prática produz um discurso fundamentalmente problematizador, reflexivo, relacional, que articula experiências pessoais e singulares com as estruturas sociais e permite compreender como as modificações estruturais são sentidas em pequena escala pelos indivíduos e grupos (MILLS, 1969; BOURDIEU, 2011).

Nessa construção desempenham papel fundamental os conceitos sociológicos. Estes, são instrumentos teóricos desenvolvidos em Sociologia para compor um sistema explicativo. Assim, os conceitos são termos (ou expressões) compartilhados com a linguagem comum, mas que tem um sentido preciso para a Sociologia, ou mesmo para cada tradição teórica dentro dela (DE SOUZA, 2016).

A linguagem sociológica é aqui pensada, portanto, como um conjunto de conceitos, categorias e teorias que conformam um esquema de percepção da vida social, e também como um discurso, como forma particular de uso da linguagem, que permite estabelecer tais esquemas e uma nova leitura do real. Ensinar Sociologia deve levar em conta o aprendizado dessas duas dimensões. 
Segundo Bautier (2007), pode-se ver a escolarização como um processo de inserir-se e aprofundar-se em formas de relação "secundária" com os saberes e com a linguagem, que são próprias da cultura letrada. Espera-se que os jovens possam realizar esse movimento de reelaboração da experiência vivida, transformando objetos e discursos primários, aquilo que conhecem e produzem de forma espontânea, em saberes e discursos de tipo secundário, distanciados da situação objetiva vivenciada. Essas reelaborações estão relacionadas ao desenvolvimento de uma forma específica de pensar, de ver e de dizer o mundo.

A reconfiguração da experiência em objeto de saber, e dos saberes escolares em saberes com significações culturais mais amplas e partilhadas socialmente é uma competência viabilizada pela linguagem, ou através de práticas linguísticas que permitem a categorização e a organização da experiência. Um segundo aspecto a ser ressaltado, portanto, é que o conhecimento científico, como parte da cultura letrada, é produzido e viabilizado através da linguagem escrita (BAUTIER, 2007).

Conforme Vygotsky (2009), a escrita difere da fala tanto na forma como no conteúdo. Sua estrutura propicia formas complexas de pensamento e abstração, pois ela exige uma consciência maior sobre a linguagem, seja para decompor as palavras foneticamente e recompô-la em sinais gráficos, seja para explicitar por meio dela tudo o que na fala e na linguagem interior é omitido. Tais características fazem da linguagem escrita uma forma privilegiada não só de registrar ou expressar, mas principalmente de organizar o pensamento, argumentar, analisar, comparar, enfim, de ampliar e produzir conhecimento.

Sendo assim, é importante considerar que ao ensinar Sociologia estamos trabalhando com teorias nas quais estão implicadas formas de pensamento conceitual e abstrato viabilizadas pela linguagem escrita e que por mais que possamos reproduzir tais discursos oralmente, que possamos debatê-los em sala, ainda assim trata-se de práticas orais letradas. A apropriação dessa linguagem, seus conceitos e formas discursivas não é imediata. Ainda de acordo com Vygotski (2009), a definição verbal de um conceito é apenas o início de um processo de apropriação, que culmina na possibilidade de fazer uso desse conceito em situação diversa daquela em que ele foi inicialmente apresentado.

Diante de tais considerações, a leitura e a produção de textos despontam como momentos propícios para promover a organização do pensamento a partir das categorias, conceitos e ferramentas usados na Sociologia. Parece ser fundamental, portanto, que os estudantes estejam envolvidos em situações de uso da linguagem 
escrita ao longo do processo de aprendizado.

Na última década, os dossiês, livros, dissertações e teses sobre o ensino de Sociologia vem se multiplicando, com enfoques variados, o que nos fornece um amplo campo de experiências sobre as quais refletir, mas tais trabalhos ainda informam pouco sobre como os professores de Sociologia vem lidando com as dificuldades dos estudantes do Ensino Médio com a leitura e a escrita. Ainda assim, a partir de pesquisa de campo e bibliográfica, parece ser correta a observação de Marpica e Gobbi (2015), segundo a qual tais práticas estão cada vez menos presentes enquanto estratégia didática, notando-se a predominância de aulas baseadas em comunicação oral.

Ocorre que ao evitarmos as atividades de leitura e escrita nas aulas de Sociologia para contornar a "dificuldade dos estudantes", a escassez do tempo de aulas e outros elementos do cotidiano escolar, acabamos por reproduzir práticas que são em parte responsáveis pelo atual cenário em que crianças, jovens e adultos frequentam as escolas e ainda assim, pouco leem ou escrevem (COLELLO, 2007).

Se as aulas se centram em exposições orais e as atividades escritas ficam restitas às avaliações do tipo "prestação de contas", nos aproximamos ao modelo descrito por Colello (2007) como “escrita escolar”, descomprometida e inócua em termos de promoção do aprendizado. Nesse modelo, desconsidera-se a dimensão interlocutiva da linguagem e,

[...] todas as possibilidades do escrever, que durante anos na história da humanidade, motivaram o homem a compor, registrar dados, transmitir informações, trocar ideias a distância, receber e enviar notícias, são, no contexto da tradição escolar, "substituídas" por outras motivações, exteriores à própria escrita como razão de ser, mas prioritárias no processo de ensino: acertar o exercício, conseguir boa nota, passar de ano, concluir o Ensino Fundamental, ingressar na faculdade [...]. (COLELLO, 2007, p. 81).

É verdade que os professores de Sociologia e das demais disciplinas com carga horária de uma ou duas aulas semanais têm escasso tempo para realizar atividades de leitura com os estudantes e que quando é possível propor atividades escritas, estas tornam-se fontes de avaliação. O que se quer destacar é que se o olhar para a essas atividades, desde sua elaboração, até a execução e avaliação, distanciar-se desse modelo em que o estudante presta contas de um aprendizado, e atentar-se para o processo de interação com a linguagem sociológica que elas representam, podemos avançar na compreensão de como incrementar as práticas linguísticas dos estudantes a partir as aulas de Sociologia.

Ao redigir seus trabalhos, ao mesmo tempo em que estão envolvidos em uma 
atividade de interação, tendo o professor ou professora como interlocutores e que constroem seus textos com o objetivo de responder satisfatoriamente às atividades escolares, os estudantes desenvolvem também uma atividade que potencialmente desencadeia o processo reflexivo e de organização de ideias. Por isso, a análise das produções escritas dos estudantes apresentou-se, nessa pesquisa, como meio privilegiado para compreender o processo de aprendizado e para avaliar as situações, práticas e propostas que favorecem o desenvolvimento das formas de pensamento e linguagem que a inserção no universo letrado e secundário dos conhecimentos supõe e que parecem ser fundamentais tanto para o ensino de Sociologia como para superarmos as dificuldades em ensinar a ler e escrever efetivamente.

\section{Objetivos e metodologia}

A pesquisa tem como objetivo analisar as produções escritas de estudantes de ensino médio em aulas de Sociologia, considerando: a presença dos conceitos sociológicos, as características do discurso adotado e a relação que estes textos estabelecem com as práticas de ensino adotadas em sala de aula. A estruturação da análise baseia-se nas contribuições da pesquisa bibliográfica relacionada ao tema.

Chatel e Grosse (2014) em avaliação sobre o aprendizado de Sociologia entre estudantes franceses de nível médio ${ }^{3}$, a partir de trabalhos escritos, identificaram que entre os estudantes que utilizavam adequadamente conceitos relacionados ao tema proposto (socialização), parte deles o fazia recitando o curso, ou apenas revestindo estereótipos com palavras do vocabulário sociológico, enquanto outro grupo demonstrou uma interpretação reflexiva, traços de questionamento e argumentação. Ou seja, a pesquisa sugere que mais que identificar o uso dos conceitos, cabe avaliar se os estudantes podem "encaixar sua reflexão nos moldes de uma problemática sociológica" (CHATEL e GROSSE, 2014, p.103).

Em sua pesquisa sobre a "relação com o saber", Charlot (1996) já se referia aos usos da linguagem, diferenciando o uso referencial, para falar das coisas "tal como são" e um uso que permite explicar o mundo, avaliá-lo, nomeá-lo enquanto objeto. Nesse caso, a linguagem é usada para dizer, mas também para refletir. Pensando assim: quais

\footnotetext{
3 Os conhecimentos de Sociologia fazem parte do programa de uma disciplina intitulada Ciências Econômicas e Sociais (CES), que é oferecida em apenas uma das opções da formação de nível médio (CHATEL e GROSSE, 2014).
} 
usos da linguagem podemos observar nos trabalhos dos estudantes? Como se referem aos conteúdos, citando-os apenas, ou refletindo sobre eles?

$\mathrm{Na}$ mesma linha, assumimos as questões de Bautier (2007): os discursos dos alunos em suas produções são característicos de um processo de secundarização? Falam apenas com referência a sua experiência particular, independentemente de uma memória de sala de aula e seus registros, ou falam como sujeitos em processo de aprendizado, interrogando-se sobre os saberes e reelaborando suas experiências a partir desse processo?

Este ponto é especialmente importante ao pensarmos o ensino de Sociologia. Como lembrado por Bourdieu (2011), a construção do conhecimento sociológico passa pela adoção de um olhar distanciado e questionador para os fenômenos cotidianos, que recusa sua naturalização, por mais familiares que nos sejam e busca explicá-los sob ótica da ciência. Para isso, faz-se necessário um esforço de problematização, de distanciamento em relação à experiência vivida, para tomá-la como objeto de estudo. É possível obervar esse distanciamento, característico do olhar sociológico, nos textos dos estudantes?

Consideramos ainda a proposição de Bakthin/Volochinov (2009), segundo a qual todo enunciado participa de uma ininterrupta corrente de comunicação verbal e que somente em relação a ela pode-se compreender o sentido da enunciação. A situação e os interlocutores determinam as dimensões e características desse enunciado, a forma como o falante se expressa, bem como os complementos não verbais desse ato. Sendo assim, é imperativo analisar os textos produzidos a partir da proposta feita na avaliação, ela mesma responsiva em relação ao que foi discutido durante o curso.

Nesse sentido, a análise dos materiais considera a relação entre docentes, estudantes e o conhecimento sociológico trabalhado em aula. Como os conceitos e categorias foram apresentados e como aparecem nos textos dos estudantes? As problematizações feitas pelas professoras e nos materiais utilizados estão refletidos nas avaliações? É possível estabelecer uma relação entre as estratégias didáticas adotadas e as produções decorrentes desse trabalho? Por fim, as situações de aprendizagem planejadas e propostas favorecem o desenvolvimento de uma escrita reflexiva?

A pesquisa de campo acontece em escolas da rede estadual paulista, sendo uma na região central, uma na zona oeste do município e uma na região metropolitana. As aulas de Sociologia são acompanhadas ao longo de um bimestre em turmas do primeiro, segundo e terceiro ano do Ensino Médio e os trabalhos escritos realizados durante esse 
período são reunidos para que sejam analisados em relação às atividades didáticas propostas.

Os trabalhos discutidos nesse artigo foram realizados no segundo semestre de 2015, em escola da região metropolitana de São Paulo e constituem a avaliação final do segundo bimestre ${ }^{4}$ em uma turma de primeiro e uma de terceiro ano, da mesma professora. Dentre o conjunto de avaliações realizadas ao longo do bimestre e o conjunto de questões propostas, foram selecionadas duas questões (uma de cada turma) com características similares em termos da proposta feita aos estudantes.

No primeiro ano, os temas trabalhados ao longo do bimestre foram socialização primária e secundária e instituições sociais, dentre as quais foram discutidas: família, igreja, escola e Estado. A questão cujas respostas serão discutidas aqui foi a última de uma sequência de dez questões da avaliação e solicitava: "Escolha uma instituição social dentre as debatidas ao longo do bimestre e cite exemplos de regras internalizadas pelos indivíduos por meio dessa instituição."

No terceiro ano, os temas foram cidadania, participação política e movimentos sociais. A primeira questão da avaliação perguntava: "Porque os movimentos sociais podem ser considerados importantes instrumentos de cidadania?"

As duas questões mobilizam conceitos centrais trabalhados ao longo do bimestre e solicitam, não uma definição, mas que se explicite de alguma forma o papel que as instituições e os movimentos sociais cumprem na sociedade, o efeito deles sobre indivíduos e grupos. Também não pedem que seja discutida uma instituição ou movimento específico (cabendo ao estudante decidir sobre um deles no primeiro ano), e ambas contém uma importante informação implícita sobre o tema central da questão: "regras são internalizadas por meio das instituições sociais"; e "movimentos sociais são importante instrumento de cidadania".

A análise que segue é preliminar e de forma alguma conclusiva, sendo apenas um recorte com potencial para fomentar reflexões sobre a relação de docentes e estudantes com as avaliações escritas. Na transcrição das respostas, procurei manter as características da escrita dos estudantes, em seu formato, grafia, pontuação, etc.

\footnotetext{
4 A rede estadual paulista esteve em greve durante 92 dias entre março e junho de 2015, razão pela qual o $2^{\circ}$ bimestre letivo ocorreu entre meados e julho e agosto do mesmo ano.
} 


\section{Escritas}

Oito dos trinta estudantes do primeiro ano que estavam presentes no dia da avaliação não responderam à questão. Outros dois responderam apenas nomeando uma das instituições sociais trabalhadas: "família" e "igreja", sem acrescentar quaisquer comentários. Interessante notar que estes últimos preocuparam-se em não deixar a resposta em branco, ainda que não tenham respondido ao que solicitava à questão. ${ }^{5}$

As demais respostas, em sua grande maioria, são fortemente vinculadas à experiência pessoal, com muito pouco distanciamento na observação das regras aprendidas. Além disso, mencionam mais aquelas regras constantemente explicitadas e cobradas, que as de fato internalizadas, como em:

família, na família temos algumas regras, pelo menos na minha, 10H00 pra chegar em casa, para dormir, ajudar nas tarefas, etc (L.L.)

Família: os exemplos que eu tenho é que tem que respeita o outro e se ajudar e seguir regras que a mãe e o pai estabelecem ou alguém mais velho (W.C.)

Escola: 1- proibido usar celular, 2- entregar atividades na data prevista, 2respeitar para ser respeitado, etc (M.B.)

Escola as regras que devem ser seguidas como chegar no horário, realizar tarefas, etc (G.S.)

Em outras quatro respostas em que se elegeu a família, predomina o senso comum sobre aquilo "que se aprende em casa",

Família, ela ensina a respeitar os outros e etc. (D.S.)

A família porque dá educação, ensina a respeitar o próximo etc (C.L.)

Família respeito, disciplina, obediencia (D. S.)

Apenas uma estudante menciona um aspecto discutido em sala sobre a família como instituição social, ainda que não teça comentários ou reflexões sobre ele:

Família:

Regra: Não pode haver família quando é constituída por pessoas do mesmo

(J. S., resposta incompleta no original)

A abordagem da família como instituição social na aula, foi planejada para provocar o estranhamento dos estudantes com relação a um padrão único de família e

5 A questão anterior na avaliação já solicitava que se nomeasse as quatro instituições trabalhadas ao longo do bimestre, sendo assim, citar apenas uma instituição na questão dez não tem efeito sobre a "prestação de contas" do aprendizado à professora, pois repete o já respondido na questão anterior. Ainda assim, esses dois estudantes parecem adotar uma estratégia de "não deixar nenhuma resposta em branco", como forma de conquistar uma avaliação mais favorável da professora. 
apresentar diferentes formatos de família existentes em outras culturas e também em nossa sociedade. A professora exibiu fotos de famílias poligâmicas, poliândricas, monoparentais, explicando tais conceitos e propôs uma discussão sobre a legalização do casamento entre pessoas do mesmo sexo em nosso país. Foi a aula mais acalorada do bimestre, em que até mesmo os estudantes mais alheios ao curso se manifestaram, referindo-se a histórias conhecidas, emitindo opiniões, argumentando. No entanto, a questão proposta aos estudantes na avaliação não remeteu a tal momento, exceto para essa estudante, que relaciona a instituição familiar a um formato específico matrimônio aceito pela sociedade.

Em quatro respostas que tratam da igreja enquanto instituição, é interessante notar que os estudantes mencionam o termo "religião" e não "igreja". Novamente, é muito marcada a experiência pessoal e a dificuldade em nomear comportamentos internalizados pelos indivíduos, ou as regras, conforme solicitado na avaliação.

\footnotetext{
Religião: Quase todas as pessoas que nascem segue a religião da familiar, que os ensinam como gostar, amar e vivem essa religião dificilmente essas pessoas mudaram de religião (C. S.)

instituição religiosa - por base da família adquiri a religião evangélica (T.S.)

Religião: entre o termo religião inclui aquela coisa de católica e evangélica assim estabelecendo regras católica: amar a deus sobre todas as coisas evangélica: depende da igreja que ser frequentar (M.F.)
}

Religião pois tem em todo lugar e muitas pessoas procurando deus, e lá tem suas regras que são respeitadas (L.C.)

Por outro lado, esses enunciados têm um caráter um pouco mais reflexivo que aqueles sobre a família e a escola. Em duas das respostas, relaciona-se a adesão a uma religião à família. Sendo assim, a própria religião é considerada como aquilo que foi internalizado. Ainda que não se aproxime de uma abordagem sociológica da religião, que não se resgate a memória de sala de aula a respeito do tema, ou definições conceituais, os enunciados refletem uma visão um pouco mais distanciada e reflexiva sobre a religião, referindo-se menos às condutas esperadas e mais ao que liga uma pessoa a uma religião ou quais as implicações disso em suas vidas.

Também é possível notar um distanciamento maior nas três respostas que trataram do Estado. Duas delas citam as leis como as regras dessa instituição e a terceira menciona a preponderância do Estado sobre as demais instituições sociais, mas os três estudantes acabaram por ressaltar uma ação do Estado: “ditar", estar "no comando". 
Estado:

- segurança das pessoas que abitam, você não pode fazer tudo o que quer sobre você tem a lei que ditam regras e sobre a lei está o estado que desenvolvem essa lei." (L.L.)

Existem regras no Estado, o Estado dita o que o povo faz, impondo leis como Música alta até certo horário

Bebida para menores é proibido

etc. (M. Q.)

Estado que está no comando de todas essas instituições sociais (E. J.)

Com relação aos conceitos que foram trabalhados ao longo do bimestre, os enunciados presentes nas avaliações trazem apenas seu uso cotidiano, aquele da linguagem corrente, para usar os termos de Bourdieu, Chamboredon e Passeron (2000). O uso sociológico de tais termos, como conceitos científicos e organizadores de uma interpretação sociológica sobre a vida social não aparece nas respostas. Deve-se, evidentemente, considerar que são estudantes no início do primeiro ano, e que não cabe aqui exigir uma precisão conceitual e sim uma familiarização com os mesmos. O que se quer destacar é que os estudantes mais citaram as instituições e as regras, que refletiram sobre elas, tal como observado por Charlot (1996) e Chatel e Grosse (2014).

Com relação às características discursivas, por sua vez, nota-se que há um distanciamento maior, e uma reflexão com maior nível de generalidade quando os estudantes trataram de instituições vividas ou sentidas de maneira também mais distante, ou menos pessoal, como a igreja ou religião, e o Estado. O número de estudantes que escolheu tratar de cada uma das instituições (família 8/20, escola 5/20, igreja 4/20 e Estado 3/20) segue uma ordem decrescente que coincide com a proximidade com que se percebe a presença de cada uma delas na vida dos indivíduos. O nível de distanciamento nos textos, por sua vez, segue em ordem inversa, ou seja, mais estudantes escolheram tratar de família e sobre ela encontramos os comentários mais pessoais, com relatos em primeira pessoa, inclusive. Já com relação ao Estado, o olhar é mais abrangente e sua ação incide não no estudante-autor da resposta, mas no povo, nas "pessoas que habitam", nas outras instituições sociais.

Para compreender essas duas dimensões do uso da linguagem (usos dos conceitos e forma discursiva), parece fundamental recorrer ao terceiro foco da análise, que é a relação de tais enunciados com toda uma corrente comunicativa que se desenvolveu ao longo do bimestre com aquele grupo. O que chama atenção, nesse aspecto, é a diferença entre a forma como os conteúdos foram trabalhados em sala e a proposta feita na avaliação. 
Se considerarmos apenas as aulas dedicadas ao tema instituições sociais, os registros de campo mostram que para todas elas, exceto para família, houve um texto teórico em que se apresentavam perspectivas sociológicas a respeito das mesmas. No entanto, nenhum deles foi lido em sala e as aulas seguiram o roteiro bastante consolidado nas práticas escolares, de anotação do texto na lousa, cópia nos cadernos e breve explicação ao final da aula ou no início da aula seguinte. Sendo assim, tais textos pouco ou nada serviram como recursos didáticos, o que se reflete no fato de que nem a professora, nem os estudantes os mobilizaram na elaboração e execução da avaliação, com exceção de um garoto, cuja resposta foi a transcrição de um fragmento do texto sobre a escola presente em seu caderno:

Escola a função mais um mecanismo de reprodução de um sistema sócioeconômico-político que mantém as desigualdades de classes sociais, gênero (masculino e feminino) (J.A.) ${ }^{6}$

A despeito de não ter discutido esses textos em sala, a professora propiciou para todas as instituições momentos de problematização, em que os temas foram debatidos oralmente, a partir de imagens, vídeo, de um relato de filme e outros recursos. Seu objetivo, segundo registros de campo, era provocar o estranhamento dos estudantes sobre o papel dessas instituições em nossas vidas e questionar a naturalização das relações estabelecidas através delas. Mas ela não acionou tais problematizações na avaliação e, consequentemente, as produções dos estudantes não as refletiam.

Para o momento da escrita dos estudantes, a proposta realizada não favoreceu nem a abordagem teórica, nem o questionamento ou a problematização que se buscou oralmente. Foram elaboradas questões diretas, que permitem respostas sucintas e objetivas, em que se citam conceitos ou definições, com pouco estímulo para uma escrita mais reflexiva. ${ }^{7}$ Situações como essas já foram destacadas por diversos autores, que as interpretam como uma estratégia adotada pelos professores para avaliar ou aferir conhecimentos sem causar dificuldades aos estudantes que "escrevem pouco" ou são "pouco familiarizados" com essas formas linguagem (Charlot, 1996, Colello, 2007; Bautier, 2007).

6 A avaliação não previa consulta ao caderno, mas fica claro que foi essa a estratégia utilizada pelo estudante. A citação do caderno começa em "mais um mecanismo..." e não se completa, tendo a estudante omitido a menção à desigualdade racial, presente no texto passado na lousa.

7 Outras questões da avaliação seguiam esse mesmo padrão, como em "O que é socialização?" "A socialização primária ocorre geralmente por qual meio?" "Quais foram as instituições sociais debatidas ao longo desse bimestre?", além de questões de múltipla escolha. 
Bautier (2007) fala sobre práticas de "sobreajustamento", quando se retiram as dificuldades de uma atividade na intenção de facilitar o trabalho dos jovens. A autora discute o quanto tais práticas acabam por obstruir a familiarização com as formas de linguagem que são justamente as que se gostaria de promover. Colello (2007), por sua vez, relaciona essa prática de facilitar as atividades escritas à prevalência ou consolidação do modelo de escrita escolar, descomprometida e desconectada das práticas sociais de uso da escrita.

Nesse sentido, os estudantes realizaram o que lhes foi proposto e que aparentemente condiz com uma "fórmula estável de enunciado", nos termos de Bakhtin/Volochinov (2009), do ambiente escolar, como pode ser notado pela quantidade de respostas em que os estudantes nomeiam uma instituição, acrescentam dois pontos ou um traço e citam uma sequência de "regras", sem acrescentar quaisquer comentários ou reflexões. ${ }^{8}$

Elaborar propostas de avaliação que provoquem uma escrita reflexiva, argumentativa, que tragam para esse momento da avaliação escrita as problematizações sociológicas (Chatel e Grosse, 2014) parece ser imperativo na tarefa de familiarizar os estudantes com essa linguagem. Poupá-los desse exercício é também uma forma de subestimá-los e de reproduzir as desigualdades no domínio da escrita.

Nas avaliações realizadas pela turma do terceiro ano, há uma diferença bastante clara em relação àquilo que foi produzido pelos estudantes no primeiro ano, em termos do distanciamento e da compreensão do tema estudado. Nas 15 avaliações realizadas, a questão foi respondida. Com relação à abordagem dos conceitos, seus enunciados podem ser divididos em dois grandes grupos. Um deles, com sete avaliações, relaciona os movimentos sociais a reivindicações e conquista de direitos:

As pessoas procura os seus direitos (S.A.)

Podem ser considerados instrumentos de cidadania pois os movimentos sociais é uma forma de um grupo buscar seus direitos (V.P.)

podem ser um importante instrumento de cidadania, pois os movimentos lutam pelos direitos do cidadão estão buscando melhoras para as minorias (N.P.)

Porque são meios de conseguir mais direitos e de dizer 'eu estou aqui e sou cidadão'. (W.S.)

8 Ou ainda, naquelas em que após nomear uma instituição, elaboram sua resposta justificando sua escolha: "Religião pois tem em todo lugar (...)", “A família porque dá educação, (...)", "Estado que está no comando (...)". 
No outro grupo, com oito avaliações, os movimentos sociais são mais fortemente relacionados às transformações sociais.

$$
\begin{aligned}
& \text { Porque graças aos movimentos sociais muitas mudanças foram feitas na } \\
& \text { sociedade e também graças a ela tiveram suas revoluções (L.M.) } \\
& \text { Sem os movimentos, nós não iriamos conseguir reivindicar nada e o país iria } \\
& \text { continuar o mesmo. (L.A.) } \\
& \text { Porque sem eles não tem como as pessoas se reunirem para manifestar para } \\
& \text { conseguir o que quer ou algo melhor para sua sociedade etc. (A.L.) }
\end{aligned}
$$

As respostas seguiram um padrão sucinto, como já observado para o primeiro ano. Chama atenção que a grande maioria delas menciona apenas um aspecto da relação entre movimentos sociais e cidadania, ou seja, não associam a luta por direitos com a transformação social, a expressão de opiniões e interesses, a participação política, etc. Ao que tudo indica, ao encontrar um elo entre "movimentos sociais" e "cidadania" os estudantes consideram ter alcançado uma resposta suficiente e não lhes parece ser necessário desenvolvê-la. Novamente, o formato da questão favorece essa atitude.

Quanto às características discursivas, pode-se dizer que os enunciados produzidos pelos estudantes têm um caráter mais argumentativo que no primeiro ano, embora os argumentos sejam pouco desenvolvidos e nem sempre haja uma elaboração sobre como os movimentos conquistam direitos ou transformações.

São considerados instrumentos de cidadania pelo o fato dos movimentos ajudar a melhorar a sociedade (A. M.)

Em três respostas nota-se uma dificuldade na redação e encadeamento da argumentação. É interessante notar, contudo, que estes estudantes são os que buscam acrescentar elementos em seus enunciados e talvez seja esse o fator que gera dificuldades, pois é mais trabalhoso fazê-lo em um enunciado curto e direto, como os que caracterizam as respostas escolares.

Porque ele ajuda os necessitados e tira a desigualdade social dando o povo o povo a saber dos seus direitos (T.S.)

por ser uma forma de protestar ou fazer o movimento social ajuda ou pelo menos da inicio a grandes coisas pelo o que os cidadãos precisam (A.S.)

Pois com eles a sociedade ira constituir de uma colaboração melhor com o movimento elas iram expressar suas opiniões ai nessa sociedade. (M.V.)

Isso sugere que tanto a interação com textos mais elaborados e dissertativos, como o exercício desse tipo de escrita devem ser fortalecidos, a partir de propostas que provoquem uma atitude mais reflexiva em relação aos temas trabalhados, em que se 
considerem múltiplos fatores envolvidos e a argumentação e o encadeamento de ideias sejam necessários e viáveis (por exemplo, considerando um tempo adequado para elaborar os textos).

Ainda quanto ao tipo de discurso adotado, o salto maior em comparação com o que se observa no primeiro ano, é o do distanciamento na abordagem do tema proposto. Os estudantes não se colocam com referência às experiências pessoais, consideram a historicidade da conquista da cidadania e das transformações sociais e não naturalizam a existência dos movimentos. Esta postura mais distanciada, característica de um discurso secundário, pode ser atribuída a vários fatores. Um deles, certamente, seria uma maturidade maior da turma. Pode-se ponderar também, que os estudantes talvez não se considerem parte de nenhum movimento social ${ }^{9}$ e por isso tenham um olhar mais característico do observador, mas eles tampouco assumem o tom de quem opina sobre tais movimentos, como poderia ser o caso.

Outro elemento que pode ter favorecido esse olhar mais distanciado e interpretativo, por parte dos estudantes é justamente o trabalho realizado pela professora ao longo do bimestre, a interação entre a turma, a docente e o conhecimento trabalhado. Para tratar dos movimentos sociais, a sequência didática foi bastante variada, incluiu uma aula expositiva de comparação dos movimentos tradicionais e contemporâneos, dois exercícios de leitura e escrita (um com o livro didático e outro com um artigo de jornal), discussões em sala que remetiam à greve de professores daquele ano e às reivindicações da comunidade escolar para a direção da escola, e seminários sobre diferentes movimentos sociais, realizados em grupos.

Ainda que o aproveitamento de algumas dessas atividades tenha ficado aquém do esperado pela professora, segundo relatado em campo, o curso propiciou um panorama mais amplo sobre os movimentos em seu conjunto, possibilitando que os estudantes percebessem elementos comuns entre eles, o que parece não ter sido alcançado com o tema das instituições sociais no primeiro ano.

Houve uma série de oportunidades de mobilizar os conceitos de cidadania e de movimentos sociais ao longo do bimestre, de falar e escrever sobre eles, de compreender seu papel na sociedade. Essa possibilidade de exercitar o uso dos conceitos em diferentes situações parece ter se refletido na aprendizagem e essa percepção também é corroborada pelas repostas dos estudantes às demais questões da

9 Apenas um estudante se coloca em primeira pessoa (no plural, "sem os movimentos, nós não iriamos conseguir reivindicar nada"). 
avaliação.

\section{Considerações}

Tratando-se de uma pesquisa ainda em andamento e de uma análise parcial do corpus de trabalhos dos estudantes, não se pretende apresentar considerações finais, mas sim destacar algumas reflexões sobre os problemas iniciais colocados na pesquisa à luz da experiência em campo e em diálogo com a bibliografia.

O processo de consolidação do espaço da disciplina Sociologia nos currículos da educação básica não é um processo de mão única. Assim como traz para a cultura escolar novos conhecimentos, docentes, linguagens e práticas, a Sociologia, ao constituir-se enquanto disciplina na educação básica, também incorpora práticas e saberes já estabelecidos naquele ambiente (MARPICA e GOBBI, 2015). O desenvolvimento da pesquisa permite observar implicações dessa incorporação no que toca às atividades de leitura e escrita.

Por mais que nas aulas os professores de Sociologia esforcem-se para desconstruir ou não reproduzir os padrões de um sistema de ensino baseado na transmissão e acúmulo de conhecimentos, em direção unívoca (do professor para os estudantes), que proponham aulas dialogadas em que os estudantes podem discutir concepções distintas, e desenvolvam estratégias didáticas para promover os processos de estranhamento e desnaturalização, nem sempre se observa a continuidade dessa postura docente nas atividades envolvendo a linguagem escrita, que parecem configurar-se ainda como um território pouco explorado e reproduzem os padrões de uma cultura escolar mais consolidada.

Para Guimarães (2015) as dificuldades dos estudantes em incorporar os conhecimentos teóricos trabalhados nas aulas a suas produções escritas levam à necessidade de refletir e rever as práticas pedagógicas adotadas, sobretudo no tocante à desnaturalização, pois não se trata de um conteúdo e sim de um comportamento intelectual a ser incentivado. Sem descartar a necessidade de um aprimoramento de nossos conhecimentos sobre didática da Sociologia, a análise das produções escritas dos estudantes nessa pesquisa, conjugada à observação de aulas, sugere que boa parte do problema reside na passagem para a escrita e não necessariamente na condução das aulas. 
Diversos fatores, como o tempo, a carga horária, o número de turmas e estudantes sob responsabilidade de um(a) docente e as exigências burocráticas da gestão escolar, levam à apropriação de modelos de avaliação já consagrados e que nem sempre condizem com o que foi proposto nas aulas. E mesmo quando as propostas de avaliação comportam uma liberdade maior para a escrita, são os próprios estudantes que lançam mão de estratégias bem estabelecidas para satisfazer às exigências das avaliações escolares e eximem-se de um exercício mais reflexivo.

Nesse cenário, observar o comportamento dos estudantes e adiantar-se a eles na elaboração das atividades escritas é importante para contornar esses aspectos da cultura escolar que não se deseja reproduzir. Do mesmo modo, rever as concepções de escrita e educação que estão por trás das práticas que adotamos ao lecionar parece fundamental. Da mesma forma que não se pode naturalizar a familiaridade com determinadas formas de linguagem, particularmente das que fazemos uso nas Ciências Sociais, tampouco se pode privar, ou pretensamente poupar os estudantes de oportunidades de familiarizar-se com elas.

O papel de mediação a ser desenvolvido pelo professor, no acesso a essas formas de linguagem características do discurso sociológico é fundamental. Para compreender esse papel e as maneiras de exercê-lo de maneira positiva, a apropriação dos conhecimentos desenvolvidos na área de linguagem e educação, do ensino da leitura e da escrita e da avaliação representam uma grande contribuição, é nessa direção que se encaminha essa pesquisa.

\section{Referências}

BAKHTIN, M. Estética da criação verbal. Trad. Paulo Bezerra. $4^{\mathrm{a}}$ ed. São Paulo: Martins Fontes, 2003.

. Marxismo e Filosofia da Linguagem. Trad. Michel Lahud e Yara Frateschi Vieira. São Paulo: Hucitec, 2009.

BAUTIER, É. Socialisation cognitive et langagière et discours pédagogique, In: FRANDJI, D., VITALE, P. L'actualité de B. Bernstein, discours pédagogique, pouvoirs, Rennes: P.U.R., 2007, p.133-150.

BOURDIEU P; CHAMBOREDON, J. C. \& PASSERON, J. C. A Profissão de Sociólogo. Preliminares epistemológicas. Trad. Guilherme João de Freitas Teixeira. Petrópolis: Vozes, 2000.

BOURDIEU, P. O Poder simbólico. Trad. Fernando Tomaz. $15^{\circ}$ ed. Rio de Janeiro: 
Bertrand Brasil, 2011.

CHARLOT, B. Relação com o saber e com a escola entre estudantes de periferia. Cadernos de Pesquisa, São Paulo, n. 97, p. 47-63, maio 1996.

Da relação com o saber: Elementos para uma teoria. Trad. Bruno Magne. Porto Alegre: Artes Médicas Sul, 2000.

CHATEL, E., GROSSE, G. O. Ensino Sociológico nos estabelecimentos de Ensino Médio: entre problemas sociais e a sociologia acadêmica. Revista Educação \& Realidade. Porto Alegre, v. 39, n.1, p. 99-111, jan./mar. 2014.

COLELLO, S. M. G. A escola que (não) ensina a escrever. São Paulo: Paz e Terra, 2007.

GUIMARÃES, M. C. O ensino de Sociologia no Colégio Estadual Lauro Corrêa: uma abordagem acerca das desigualdades sociais. In: HANDFAS, A. MAÇAIRA, J. P., FRAGA, A. B. (orgs.). Conhecimento escolar e ensino de sociologia: Instituições práticas e percepções. Rio de Janeiro: 7 Letras, 2015, pp. 156-167.

INAF Brasil 2011. Indicador de alfabetismo funcional. Principais resultados. Relatório. Instituto Paulo Montenegro; Ação Educativa; IBOPE Inteligência, São Paulo, 2012. Disponível em: http://www.ipm.org.br/ptbr/programas/inaf/relatoriosinafbrasil/Paginas/inaf2011_2012.aspx Acesso em 29. fev. 2016.

DE SOUZA, E. K. Linguagem e ensino de sociologia: reflexões sobre a apropriação da linguagem sociológica. Revista Em Tese, Florianópolis, v. 13, n. 1, p. 141-160, jul. 2016. Disponível em: <https://periodicos.ufsc.br/index.php/emtese/article/view/18065023.2016v13n1p141/32149>. Acesso em: 24 jul. 2016.

MARPICA, N. S. e GOBBI, M. A. Cultura escolar e ensino de Sociologia: a história da disciplina escolar e sua prática cotidiana. Revista Café com Sociologia. Piúma/ES, v. 4 n. 3 dezembro, 2015. Disponível em: http://revistacafecomsociologia.com/revista/index.php/revista, acesso em 05 de fev. de 2015.

MILLS. C. W. A Imaginação Sociológica. Rio de Janeiro: Ed. Zahar, 1969.

SAO PAULO. Secretaria de Estado da Educação. Sumário Executivo. SARESP, 2014. v. 1. Secretaria de Estado Da Educação, Vunesp: São Paulo, 2015. Disponível em: http://file.fde.sp.gov.br/saresp/saresp2014/Arquivos/SUMARIO_EXECUTIVO.pdf Acesso em 29 de fev. 2016

RIBEIRO, V. M. (org.). Letramento no Brasil. São Paulo: Global, 2003.

VYGOTSKY, L. S. Estudo do desenvolvimento dos conceitos científicos na infância. In: VIGOTSKI, L. S. A construção do pensamento e da linguagem. São Paulo: Martins Fontes, 2009, pp. 241-394. 